\title{
Chapter 4 \\ Urbanization and Infectious Diseases: General Principles, Historical Perspectives, and Contemporary Challenges
}

\author{
Raquel Reyes, Roy Ahn, Katherine Thurber, and Thomas F. Burke
}

\subsection{Background}

In 2009, a major demographic line was crossed: for the first time in history, the majority of the world population lived in cities rather than in towns and countryside (Fig. 4.1). This shift has been occurring over the past 100 years, with the most rapid rate of urban growth occurring over in the latter half of the twentieth century. Urban centers in the more developed regions of the world (i.e., North America, Australia, New Zealand, and Europe) experienced earlier growth in the 1920s-1950s, and since then, the rapid rate of urban growth has been concentrated in the cities and towns of developing nations [1].

According to the United Nations Population Division, the urban areas of the world are expected to absorb the entirety of the projected world population growth through 2050. The majority of this growth is expected to occur in less developed regions and countries such that by mid-century, $54 \%$ of the world's urban population will be concentrated in Asia and $20 \%$ in Africa. China and India together are

\footnotetext{
R. Reyes, M.D., M.P.A. ( $\square)$

Division of Global Health, Department of Emergency Medicine, Massachusetts General Hospital, Boston, MA, USA

Harvard MGH Medicine \& Pediatrics Program, Departments of Internal Medicine and Pediatrics, Massachusetts General Hospital,

Boston, MA, USA

e-mail: rreyes1@partners.org

R. Ahn, M.P.H., Sc.D. • K. Thurber, A.B. • T.F. Burke, M.D.

Division of Global Health, Department of Emergency Medicine,

Massachusetts General Hospital, Boston, MA, USA
} 


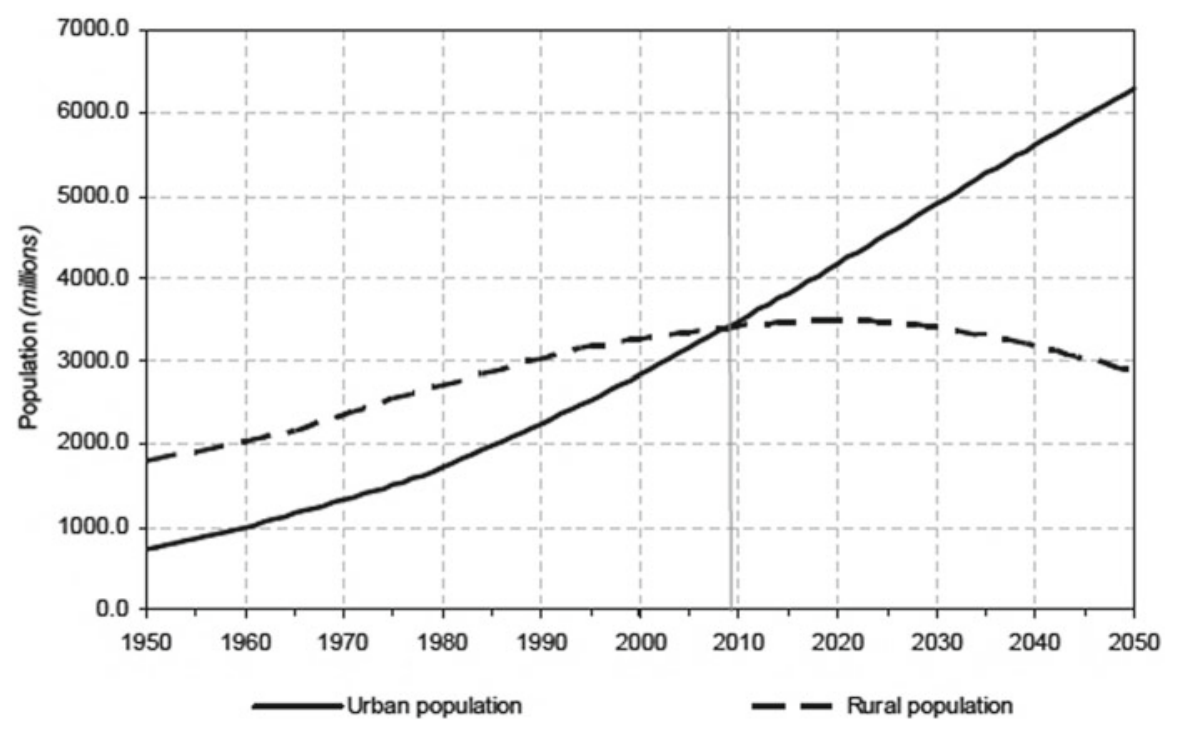

Fig. 4.1 Urban and rural populations of the world, 1950-2050. Source: United Nations Department of Economic and Social Affairs, Population Division. World Urbanization Prospects: The 2009 Revision. New York 2010. Reprinted with permission of the United Nations

expected to account for approximately one-third of the increase in the world urban population in this timeframe [1] (Fig. 4.2).

This chapter will use the term "urbanization" to refer to this demographic shift. Urbanization is the result of migration from rural to urban locales as well as the imbalance between death and fertility rates in urban and rural locales - that is, the proportionally higher ratio of births vs. deaths in cities compared to countryside. It is important to recognize, however, that "urban" and therefore "urbanization" are terms that are not easily fixed. The United Nations Statistics Division recognizes that "because of national differences in the characteristics which distinguish urban from rural areas, the distinction between urban and rural population is not amenable to a single definition applicable to all countries" [2]. Nevertheless, for the purposes of this discussion, we will use the term "urbanization" to refer most basically to the demographic shift from less densely populated localities to more densely populated localities. Additional assumptions regarding the implications of urbanization will be explicitly addressed throughout this chapter.

The effect of urbanization on health trends, morbidity, and mortality are numerous. In more developed countries and industrialized centers, for example, violent crimes, drug abuse, and motor vehicle accidents are more common health problems than in rural areas. Environmental pollutants in industrialized centers across the spectrum of more and less developed nations have a deleterious impact on health. 


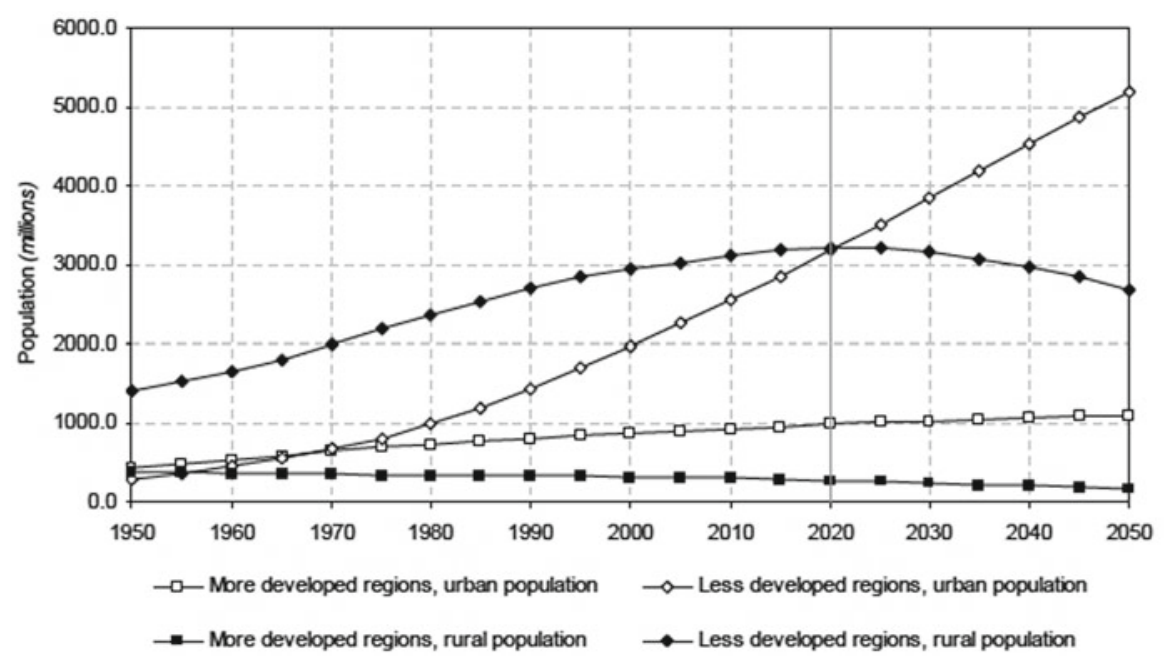

Fig. 4.2 Urban and rural populations by development group, 1950-2050 Source: United Nations Department of Economic and Social Affairs, Population Division. World Urbanization Prospects: The 2009 Revision. New York 2010. Reprinted with permission of the United Nations

Rapid growth of urban centers with poor urban planning and little capacity to meet the needs of a rapidly growing population often leads to the development of slums and shantytowns. Sanitation and waste removal, safe drinking water, secure housing, and access to adequate nutrition are other important challenges of urbanization. This chapter focuses on the infectious diseases implications of urbanization, which interrelate with the other health concerns listed above.

Along with war and famine, infectious diseases have been a leading cause of death and disability in developing societies for as long as history has been recorded. The field of modern medicine emerged around the study of infections, understanding their transmission, and developing ways to treat them with antibiotics as well as to prevent them with vaccines.

Infectious diseases, by definition, persist and thrive depending on how and how easily they are transmitted, as well as how easily they evolve over time in response to medical intervention. Infectious diseases are propagated via different forms of exposure, including exposure of an uninfected individual to the infected droplets, feces, or bodily fluids of another individual or exposure of an uninfected host to the blood or saliva of an infected vector. In the case of skin flora that can lead to serious infections, the exposure may be touch alone. With greater contact between infected and uninfected individuals, the opportunity for infections to spread increases. Urbanization necessarily provides more opportunity for contact and exposure and therefore has great implications for the transmission and the evolution of infectious diseases around the world. 
Drawing on both historical and contemporary perspectives, this chapter will discuss urbanization as it pertains to epidemics and pandemics, specific considerations for developing countries, and implications of urbanization and infectious disease in more developed countries.

\subsection{Urbanization, Epidemiology, Epidemics, and Pandemics}

Among the most intuitive manifestations of the interrelatedness of population density and infectious diseases are epidemics and pandemics. Throughout recorded history, epidemics have changed the world and influenced the trajectory of nations as well as science, medicine, and health. From plague to smallpox to more recent outbreaks of influenza and SARS, population trends influence and are influenced by infectious disease. The next section lays a basic framework for understanding the importance of shifting population demographics to epidemics and pandemics through a brief review of critical epidemiological principles, followed by historical and contemporary case examples of epidemics and pandemics.

\subsubsection{Emergence of the Field of Epidemiology}

The field of epidemiology was born of the desire to understand how disease is spread and propagated, particularly during times of epidemics. The Centers for Disease Control defines epidemiology as "the study of the distribution and determinants of health-related states or events in specified populations, and the application of this study to the control of health problems" [3]. The recognition of the importance of population characteristics to spread of disease has informed the field of epidemiology from the outset, and modern epidemiologists develop statistical and mathematical models that incorporate population characteristics to predict disease transmission and evolution as well as to anticipate possible interventions to control them.

\subsubsection{Mathematics of Epidemics}

The field of epidemiology has bourgeoned significantly since its origin in the early 1900s, and the mathematics involved can be extremely complex. Several variables are basic to the mathematics of epidemics [3, 4]. Models for describing epidemics are based upon the reproductive rate of a given disease - that is, the number of individuals infected directly by the primary case (the first infected person) during the time when she/he is infectious. The reproductive rate is itself determined by the attack rate of the disease (i.e., the risk of transmission in any given encounter), as well as the number of encounters the primary case would have, on average, during the infectious period of the disease. In other words, the greater the population 
density, the greater the number of encounters and the greater the reproductive rate. There are other factors that determine how a disease will be spread, including acquisition of immunity during an outbreak, existing immunity, the rate at which infected and susceptible individuals enter and leave the community, as well as the different types of encounter required for disease spread (i.e., via droplets, fecal-oral route, vectors, etc.). Population density is one of the most basic variables that affects the duration and impact of an epidemic.

Another important factor, particularly when considering the implications of urbanization, is the rate of entry and exit from the community. A significant proportion of the increase in urban population is due to the migration of people from rural areas to urban areas. As we will discuss in more detail further on this chapter, this can allow for the importation of diseases that were formerly confined to rural areas to urban centers where there may be increased opportunity to spread. This can also allow for increased opportunity to spread if, due to lack of prior exposure, migrants to a given area are more susceptible to a disease that is endemic to that area. In addition, as globalization continues and travel increases among the major cities both nationally and internationally, diseases can be propagated between and among urban centers. This can lead to farther-reaching - even worldwide-outbreaks of disease. Historically, travel by boat or train has enabled the transmission of endemic diseases to novel populations, causing outbreaks of diseases such as measles and smallpox and contributing to the decimation of native peoples. More recently, however, air travel has expedited the movement of airborne pathogens [5]. Viruses can now travel across the world within 24 hours, rather than within days. This statistic becomes even more powerful when considered together with the fact that more than one billion individuals worldwide travel by airplane each year $[6,7]$.

Another important factor in the mathematics of disease spread, as mentioned above, is the level of susceptibility in a given community. Once a certain level of immunity against a given disease is achieved, either through the conferring of immunity to infected individuals who survive an exposure or through vaccination, the reproductive rate is necessarily reduced as the risk of transmission in a given encounter is decreased. Limits to the spread of disease and the propagation of an epidemic occur when enough individuals in a community are immune to the disease such that the likelihood of an infected individual encountering a susceptible individual is very low. This is the basis for the concept of "herd immunity." The level of immunity required to prevent or interrupt a disease outbreak varies depending on the pathogen. Vaccination programs, which are discussed next, aim to reduce the percentage of individuals susceptible to a given disease and, ideally, achieve high enough rates of immunity to eradicate it.

\subsubsection{Vaccines}

Edward Jenner is credited as the inventor of the vaccine against smallpox (derived from cowpox lesions) in the late 1700 s, although several sources credit a Chinese 
Buddhist nun with the earliest recorded practice (as early as the year 1,000) of inoculating people with smallpox for protection from the disease through use of ground scabs inhaled intranasally [8]. Inoculation, also called variolation, was likely also practiced in Africa, Turkey, and India long before the 1700s when the practice became more common in England and the rest of Europe and ultimately led to modern vaccination [9]. Louis Pasteur was the next to develop a successful vaccine, against rabies, in 1885 . The late 1800 s and 1900 s subsequently saw the development of vaccines against plague (1897); cholera (1917); typhoid (1917); diphtheria (1923); pertussis (1926), tuberculosis (BCG, 1927); tetanus (1927); yellow fever (1935); influenza (1945); polio (1955); measles (1963); combined measles, mumps, and rubella (1971); hepatitis B (1982); Haemophilus influenzae type B (1990); varicella (1995); hepatitis A (1995); and rotavirus (1998) [10, 11].

The success of vaccination programs is exemplified by the end of smallpox; the last indigenous case of smallpox occurred in 1977 in Somalia, and in 1980, the Global Health Assembly declared smallpox eradicated. Other successes include the elimination of wild-type polio from most countries in the world. In 2003, measles was declared to no longer be endemic in the Americas [12].

The importance of vaccination to the prevention of epidemics cannot be overstated. To maintain these successes moving forward, vaccination programs will have to be expanded to meet the needs of a growing population. Failure to do so will likely lead to resurgence of vaccine-preventable diseases, as in the recent urban outbreaks of yellow fever in several West African cities including Abidjan, Ivory Coast (2001 and 2008), Dakar, Senegal (2002), and Bobo-Dioulasso, Burkina Faso (2004). These outbreaks were likely catalyzed by lower vaccination rates in conjunction with increasing population density and overcrowding conditions favorable for the Aedes spp. mosquitoes that carry the virus [13]. Even in developed countries like the USA, vaccination remains an issue. Measles resurged in Southern California between 1988 and 1990, predominantly in urban young adults and children under 5 years of age who had not yet been vaccinated. Outbreaks occurred within schools, colleges, detention facilities, and other institutions in urban areas. In order to control these outbreaks, schools required immediate immunization of non-immunized children and many re-immunization programs were launched [14]. Finally, vaccination is not only a key to prevention of epidemics but is also a cornerstone of curtailing the spread of disease during epidemics and pandemics.

\subsubsection{Case Examples of Pandemics}

To illustrate the principles described above, the following section describes pandemics from the fourteenth century to the twenty-first century, including plague, Spanish flu, severe acute respiratory syndrome (SARS), and modern influenza pandemics. The critical role and context of the urban environment in each of these historical and contemporary pandemics is also described. 


\subsubsection{Plague}

The plague has been responsible for numerous outbreaks and three pandemics in recorded history, most infamously, perhaps, during the fourteenth century in Europe where it was subsequently referred to as "The Black Death." Most estimates are that 50-75 million people worldwide, including about one-third to one-half of all fourteenth century Europeans, succumbed to the plague [15]. The plague was transmitted along trade routes by fleas carried on vermin and other animals infected with different biovars of the bacillum Yersinia pestis. There has been some debate over the exact numbers of the infected, and even whether Yersinia pestis was the true, sole pathogen responsible $[16,17]$, but it is widely agreed that "The Black Death" changed European history.

Transmission of plague is dependent on the interaction among vectors (fleas) and hosts (rats, humans, other animals). Although most plague is transmitted in the bubonic form, evolution to pneumonic plague can lead to direct transmission from person to person. Early globalization, such as trade routes from China along the Silk Road into Europe and from seaport to seaport, allowed for the rapid propagation of plague, with up to thousands of people newly infected every day [18]. Recognition of the importance of the migration of traders and their wares into urban centers of trade and industry led to early attempts at outbreak control including quarantines, movement restriction, and closure of ports to ships coming from affected countries [18]. The risk of spread from rats to humans is now known to be related to the population density of rats, the level of flea infestation per rat, as well as the level of bacteria in both the rats and their fleas [19-21]. Although the epidemiology and ecology of ancient plague are certainly more complex than this, the importance of early urbanization in early plague pandemics is clear if not clearly understood.

\subsubsection{2 "Spanish" Influenza}

The Spanish influenza pandemic of 1918-1919 killed millions of people worldwide, with recent estimates as high as 50 million and some evidence to suggest that urban areas had higher mortality [22]. By that point in history, the field of epidemiology was taking shape. Alongside improved ability to identify microscopic pathogens as well as greater understanding of pathogen transmission and immunologic defense mechanisms, there was greater focus on public health interventions. The influenza vaccine would not be developed until 1945, however, and quarantine was still the mainstay of prevention during influenza outbreaks [23].

Non-pharmacologic interventions to reduce transmission of influenza were based on reducing points of contact among infected and noninfected individuals. These interventions included "social distancing" policies such as closings of schools, churches, and theaters, as well as prohibitions on large public gatherings. Recent analyses of historical data have demonstrated that such interventions, when implemented early, were associated with approximately 50\% lower peak death rates and lower cumulative excess mortality [24]. The duration of these interventions also had 
an effect; when cities relaxed these restrictions, the epidemic returned with a rebound in morbidity and mortality [24-26]. Another study used mathematical models to demonstrate that the number of infected individuals to which a healthy individual is exposed also may correlate with mortality - that is, the greater the exposure, the more severe the illness and the higher the case fatality rate [27]. These studies have led many public health experts to argue in favor of a multipronged approach including early, sustained non-pharmacologic interventions alongside use of antivirals and vaccine development in the event of another influenza pandemic.

\subsubsection{Severe Acute Respiratory Syndrome (SARS)}

Severe acute respiratory syndrome (SARS) was the first worldwide outbreak of the new millennium and perhaps the most impressive demonstration of the interrelatedness of urbanization, globalization, and viral spread. SARS is now known to be caused by a novel coronavirus, thought most likely to have been carried in animals prior to introduction to humans. The first people infected with SARS lived outside of the city of Guangzhou, China. It was subsequently spread from an infected patient to hospital staff, one of whom traveled to Hong Kong and stayed in a hotel where he infected 16 other people, who then went on to carry it to other hospitals and other countries around the world. In Hong Kong, nearly half of SARS infections were acquired in health centers [28]. In Toronto, health centers were also epicenters of nosocomial spread [29, 30].

The SARS pandemic began outside of a major city, was brought to a major city, and from there was spread to other major cities around the world. As was highlighted above in reference to the bubonic plague, globalization and urbanization tend to go hand in hand. In modern times, international travel via aircraft allows for transmission from one major urban center to other major urban centers across the world within hours, catalyzing the process and allowing regional epidemics to become global pandemics within a matter of weeks or even days.

\subsubsection{Avian and Swine Influenza}

Earlier in this chapter, the epidemiology and lessons learned during the 1918 influenza outbreak were reviewed. This section will briefly discuss the ways that urbanization influences modern outbreaks of influenza. As with SARS, such factors include rapid spread via infected droplets in crowded centers (including health facilities), increased international travel, and animal to human to human transmission. Shifting animal demographics related to urbanization may also play a role in the evolution of viral outbreaks.

Influenza strains infect a variety of birds, both wild and domestic. Although relatively little is understood regarding the mechanisms by which cross-species transmission occurs, infected poultry, pigeons, and swine tend to play a role in the outbreak of novel strains of influenza that can subsequently cause significant morbidity 
and mortality among humans [31]. H5N1 Avian influenza is now epidemic among poultry and likely some migratory birds as well. When H5N1 is transmitted to humans, the route appears to be via direct contact with infected birds rather than via contact with other infected humans. This explains why the H5N1 virus did not become epidemic or pandemic among people. In the era of urbanization and globalization, however, once genetic reassortment does allow for efficient human to human transmissibility, a handful of infections can lead to a worldwide pandemic.

The most recent H1N1 influenza pandemic, for example, was caused by an influenza virus that was a reassortment among human, avian, and swine strains of the virus $[32,33]$. The index case was in Mexico, and the virus rapidly spread from there throughout the world via air travel. Unlike seasonal flu, such influenza pandemics are rare. There were only three influenza pandemics in the twentieth century, in 1918, 1957, and 1968. This is because in order for an influenza virus to cause a pandemic, three conditions must be met: first, the viral strain must be antigenically novel such that the population has little or no preexisting immunity; second, the strain must be transmitted to humans; and third, the strain must be efficiently transmitted from person to person $[34,35]$. Once these conditions are met, particularly in the age of urbanization and globalization, worldwide spread occurs rapidly. As with SARS, all of the index cases in the early weeks of the H1N1 pandemic of 20092010 could be traced to air travel from the index city [36].

Changing human population dynamics also influence animal population dynamics. In more remote and rural areas, localized farming is common. As populations shift, however, large agribusinesses are developed in order to supply urban populations with meat, poultry, and produce. As a consequence, animals are often kept in crowded conditions that may allow for rapid transmission of disease. These large animal farms are also points of multiple, sustained contact between humans and birds or swine, which may increase the opportunity for viral mutation to take place. Similarly, transport of live animals to large markets in urban centers can be a potential point of ignition.

\subsection{Urbanization and Specific Infectious Diseases}

Urbanization affects the spread of infectious diseases in both developed and developing countries, in wealthy enclaves as well as informal settlements. However, as the World Health Organization has described, disease threats disproportionately affect the urban poor and socioeconomic gradients are evident across many diseases [37]. The following section provides examples of major diseases - that is, those that affect large numbers of people - with a special emphasis on these diseases' impacts on urban residents. It is intended to provide an overview of selected diseases and evidence of their importance in the age of urbanization; however, it does not purport to provide exhaustive coverage of infectious diseases related to urbanization, which are numerous and varied. Furthermore, it is important to note that these diseases affect all countries, regardless of countries' stages of economic development. 


\subsubsection{Water and Sanitation-Related Diseases}

Approximately one-third of the world's population lacks access to clean water, and nearly $40 \%$ lacks access to "improved sanitation facilities" for safe disposal of human waste [38]. While people living in rural areas have the least access to clean water and adequate sanitation, urban dwellers, especially those in developing countries, still face major water and sanitation challenges. For example, sanitation rates differ substantially between urban areas of developing countries (71\%) and urban areas of developed countries (100\%) [38]. Furthermore, some health experts posit that urbanization will bring wild animals - and their waste-into closer contact with drinking supplies for humans, thereby increasing the risk for waterborne zoonotic infectious diseases [39].

According to the World Health Organization, nearly two million diarrhea-related deaths are reported each year [38]. Fecal matter in water consumed by households can lead to diseases such as cholera, cryptosporidiosis, giardiasis and typhoid, among others [40]. The urban slum environment is fertile ground for these diseases, due in large part to overcrowded housing conditions, lack of availability of treated water, and lack of adequate sanitation facilities. Cholera outbreaks, for example, have been reported in urban slums in various parts of the world, ranging from Kolkata, India, and Jakarta, Indonesia, to Nairobi, Kenya, and Kampala, Uganda $[41,42]$. Specific studies have implicated factors such as the construction of pit latrines in close proximity to wells (from which people draw their drinking water) in the fecal contamination of water sources [43]. Similarly, researchers investigating a 2007 typhoid outbreak in a West Bengal, India, slum suggested that Salmonella typhi bacteria in the fecal matter from victims were carried via open sewage drains, which then contaminated nearby unchlorinated drinking water sources [44].

Several studies have examined the water storage practices of urban residents in resource-poor areas. A study of the Parque Universitario slum in Fortaleza, Brazil, found a higher likelihood of fecal matter presence in household tap water stored in clay pots rather than in capped plastic bottles. The authors posit several explanations for the modes of transmission of fecal matter in these "wide mouth" clay pots: "scooping with contaminated hands in the container, manually clearing blocked filters and inadvertently contaminating [water storage] vessels during cleaning" [45]. Overall, it is notable that $30 \%$ of the water samples in the study contained fecal material.

Strategies to reduce the incidence of waterborne infectious diseases are numerous and varied. The World Health Organization has adopted a "household water treatment and safe storage" (HWTS) framework for preventing diarrheal disease. Water treatment techniques include the use of bleach, chlorine, and filters and the boiling of water, among other simple, cheap methods [46]. In terms of water storage, a study of urban dwellers in South India found that the practice of storing water in brass containers significantly decreased the presence of $E$. coli compared to other types of storage containers [47]. Other scientists have argued for a holistic approach to addressing the water and sanitation needs of slums. A study in Ahmedabad, India, demonstrated that "slum upgrading" could significantly reduce incidents of waterborne illness. Slum upgrading was defined as creating "connections to a water 
supply for individual households, underground sewage for individual households, toilets for individual households, storm water drainage, stone paving of internal and approach roads, solid waste management, and street lighting" [48].

Reducing diarrheal illness related to urbanization will require not only addressing the current problems borne of rapid migration with virtually no urban planning - that is, "slum upgrading" - but also curtailing the development of slums in the first place.

\subsubsection{Vector-Borne Diseases}

As demographics shift from rural to urban, and as urban centers increasingly encroach on adjacent deserts, forests, and fields, human hosts may be newly exposed to diseases spread by fleas (plague), flies (leishmaniasis), mosquitoes (malaria, yellow fever, dengue, Japanese encephalitis), and ticks (Lyme, Babesia). When migrants from rural areas bring livestock with them to urban centers (often in slums or shantytowns on the outskirts of cities), vector ecology is also affected.

For example, over the latter half of the last century, the incidence and worldwide distribution of dengue has been increasing [49]. Dengue is spread by the same Aedes spp. mosquitoes that also carry yellow fever. Interestingly, dengue fever, in contrast to many of the other vector-borne illnesses, is primarily an urban problem. The Aedes mosquitoes live in and around houses. When a dengue epidemic occurs, it begins in cities and spreads centrifugally outward to neighboring city areas, suburbs, and towns [50]. The increasing incidence of dengue and dengue hemorrhagic fever has been tied to population growth, urbanization, and poor urban planning leading to poor water sanitation and human solid waste reservoirs for the mosquitoes that transmit the infection (e.g., tires, plastic containers) [13, 49].

Other vector-borne illnesses such as yellow fever and leishmaniasis have also been affected by urbanization. As discussed earlier, the recent epidemics of yellow fever in West Africa are most likely due to a combination of inadequate vaccination coverage, increasing population density, as well as the environmental factors just described that allow for proliferation of Aedes spp. mosquitoes. A combination of shifting population dynamics, deforestation, and expansion of nonimmune human populations into endemic areas has been correlated with increased transmission of visceral leishmaniasis around the world [51].

Finally, we turn our attention to malaria. The problem of resistant malaria is described elsewhere in this book. The remainder of this section discusses the impact of urbanization on malaria.

Malaria, which is a vector-borne disease caused by selected Plasmodium species, is a leading global killer, especially of children. In Africa, $20 \%$ of all child deaths are due to malaria [52]. According to the World Health Organization, there were nearly 250 million cases of malaria in 2008, in 100 countries [53]. However, the majority of the estimated one million deaths due to malaria each year occur in Africa [54]. 
Data from sub-Saharan Africa suggests an increased risk for malaria in rural areas when compared with urban areas. For example, the Plasmodium falciparum entomological inoculation rate, defined as the number of "infective bites per person per annum," [55] is considerably lower in sub-Saharan African urban areas than in rural ones [56]. There may be several reasons for this. First, unlike for Aedes spp. mosquitoes, urban areas are inhospitable environments for Anopheles mosquito development, the major vectors of the Plasmodium parasites that cause malaria [57]. City pollution is thought to inhibit larval development of Anopheles mosquitoes [58]. In addition, city dwellers have increased access to insecticide-treated nets (ITNs). Urban residents have a rate of ITN use three times higher than that of rural residents in sub-Saharan Africa. Finally, urban residents live in closer proximity to health-care facilities compared to their rural counterparts, affording them greater access to treatment for malaria once infected [54].

Nevertheless, malaria remains a major urban health concern. Malaria experts have estimated that 200 million city dwellers in Africa are at risk for malaria [59]. Some experts note that characteristics of rapid urban development (e.g., open wells, poor sanitation in slum areas) may provide opportunities for water to pool and, consequently, for malarial vectors to breed $[55,60]$. This may be especially true among poorer sections of cities: urban malaria prevalence rates in Africa have been shown to be inversely correlated with individuals' socioeconomic status [61]. Furthermore, there is an emerging concern that many city residents lack sufficient immunity to malaria [58] and that urban children in endemic countries who regularly visit rural areas may be at increased risk for malarial anemia [62]. In cities where farming activities exist, so, too, does the potential for the urban environment to support anopheline mosquito development [58]. Lastly and particularly concerning is recent evidence from slum areas in sub-Saharan African cities that suggests that various Anopheles species are beginning to adapt to polluted city water sources $[13,57,58]$.

\subsubsection{Respiratory Infections: Highlight on Tuberculosis}

The epidemic and pandemic potential of viral respiratory infections such as influenza and SARS in the age of urbanization and globalization was reviewed previously. This section focuses on the bacterial airborne disease tuberculosis (TB), which is caused by Mycobacterium tuberculosis. 1.7 million people died from TB in 2009; $85 \%$ of all global TB cases occurred on the African and Asian continents [63]. TB is also an urbanization and health issue; high rates of TB have been reported in large cities throughout the world $[64,65]$, prompting concerns of possible urban TB epidemics in the future as more people migrate into cities [64].

Experts posit various explanations for the proliferation of TB in urban settings. First, overcrowding is known to be positively correlated with the incidence of TB [64, 66]. For example, one study of neighborhoods in Harare, Zimbabwe, found that living in a home with two or more people per room was a significant risk factor for TB [67]. 
Dubbed by WHO as a "disease of poverty," the urban poor are particularly at risk for TB infection due not only to overcrowding but also to higher rates of underlying malnutrition and comorbidities including HIV [66, 68]. One study in Mexico documented that neighborhoods with low socioeconomic status (SES) had higher TB morbidity and mortality rates compared to higher SES neighborhoods [69].

Numerous other studies underscore the dilemma of poor urban dwellers who, due to lack of knowledge about TB and lack of access to quality health-care services, often remain undiagnosed or, once diagnosed, are not able to complete TB treatment $[68,70,71]$. A recent study of 106 private physicians in Mumbai found that these physicians prescribed more than 60 different treatment regimens for TB, and less than $10 \%$ of these physicians prescribed regimens meeting the study authors' definition of a "correct prescription" for TB drug treatment [72].

The dangers of TB are compounded by the emergence of multidrug-resistant TB (MDR-TB) and extensively drug-resistant TB (XDR-TB), discussed in detail elsewhere in this book. MDR-TB accounted for 440,000 cases worldwide in 2008 [63]. MDR-TB has been reported in many large cities, such as Mumbai, Sao Paulo, and Shanghai $[13,71,73,74]$ and in smaller numbers, XDR-TB cases have been documented in many cities around the world [75, 76]. New York City alone reported 19 cases of XDR-TB between 1993 and 2006 [77]. Data from Mumbai, India, found much higher rates of MDR-TB in Mumbai, compared to rural areas of India [78]. In China, there is concern that workers from rural areas infected with TB are migrating to the cities in search of work, consequently transmitting TB and possibly contributing to TB drug resistance $[71,79]$ There is concern that these Chinese migrants are neither seeking nor receiving appropriate, timely TB treatment [80]. The case fatality rate associated with MDR-TB is much higher than for nonresistant TB, especially if left untreated. Researchers studying TB in a poor section of Sao Paolo, Brazil, for example, reported a $60 \%$ mortality rate among the non-HIVinfected MDR-TB patients in the study sample [74].

\subsubsection{HIV/AIDS (and Other Sexually Transmitted Infections)}

HIV/AIDS is by far the most widespread epidemic in the world, with the greatest morbidity and mortality. A chapter in this book focuses on the HIV pandemic; this section will briefly highlight some ways that urbanization may impact on the propagation and evolution of the virus.

HIV is distinct from the other examples discussed in this chapter in that it transmitted via infected bodily fluids - that is, through blood exposure, sexual exposure, and during pregnancy, delivery, and breastfeeding - rather than via droplets, vectors, or fecal-oral contamination, which are perhaps more intuitively and directly related to urbanization. Urbanization may, however, influence behaviors that affect the risk of acquiring HIV, including alcohol and drug use as well as sexual behavior. Migrants to urban centers are often young people who are separated from their families and traditional social structures. In addition, the disparity 


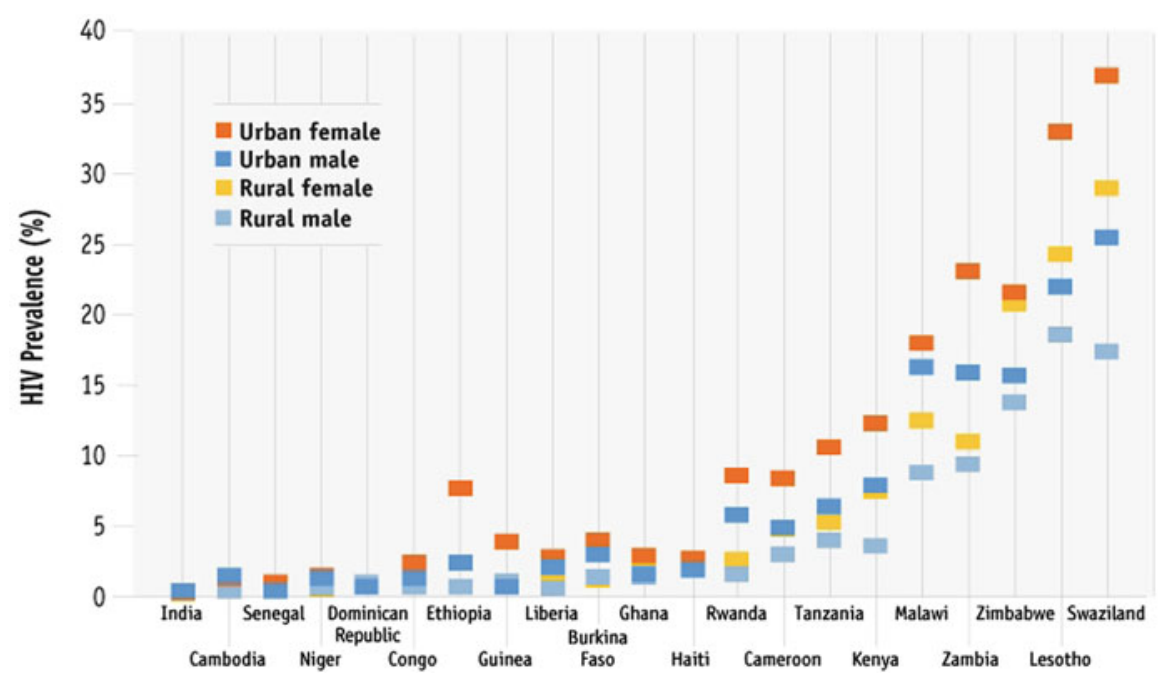

Fig. 4.3 HIV prevalence by gender and area of residence 2003-2008. Source: WHO calculations based on data from Demographic and Health Surveys (DHS) 2003-2008. Reprinted with permission from $\mathrm{WHO}$

between the rich and poor in urban environments can be stark. Migrants are typically seeking opportunity, coming to the city from a less privileged socioeconomic background. The confluence of these factors may lead to higher-risk behaviors.

According to the U.N., there were 2.6 million new cases of HIV infection in the world in 2009, and 1.8 million of these new cases were in sub-Saharan Africa alone [81]. In many sub-Saharan African countries, such as Zambia and Kenya, HIV prevalence rates among 15-49 year olds are higher in urban areas than in rural areas [82] (Fig. 4.3).

Considerable attention has been paid to the issue of high-risk sexual behaviors among workers who migrate to cities in search of work [13, 83, 84]. Much of this literature focuses on Asian countries. In China, where an estimated 140 million migrants reportedly exist, studies have described risky sexual practices and poor knowledge about HIV among male migrant workers [85], and even among migrant workers' school-aged children [86]. A study of male taxi drivers from rural Bangladesh who migrated for work to the capital, Dhaka, reported that approximately $60 \%$ of respondents had recently engaged in sex with commercial sex workers without using condoms [87]. Several studies of commercial sex workers in cities of India have documented the elevated risk of HIV infection among this population [88]. The phenomenon of young women and girls migrating to cities, becoming engaged in commercial sex work, and contracting HIV is well documented. A recent study of 287 Nepalese women and girls who had been sex-trafficked into urban brothels in India and then returned to Nepal revealed a $38 \%$ HIV-positive rate among these victims [89]. Seventeen of these women and girls were also found to have TB [90]. It appears that sexual behaviors of migrant workers will help fuel the 
spread of HIV in cities - but also in the rural communities to which these workers will return.

Similar factors likely contribute to the transmission of HIV in sub-Saharan Africa, which has seen an impressive redistribution of populations and rise of ruralto-urban migration. Between 1960 and 1980, the crude population density more than doubled across sub-Saharan Africa and there was a nearly tenfold increase in the number of cities with populations exceeding 500,000 [91].

Linkages between urban slums/informal settlements and HIV have been described in the literature. In Kenya, an analysis of the Nairobi Cross Sectional Slum Survey found that slum residents who had either migrated from economically poor rural villages or from other slums were more likely to engage in risky behaviors with respect to HIV/AIDS (i.e., condom use and number of sexual partners) than other slum residents [83]. These findings are consistent with a recent study of five African cities - Accra, Dar es Salaam, Harare, Kampala, and Nairobi-which reported that living in a slum predicted riskier sexual behaviors [92]. Some researchers have posited that in migrating from rural areas to cities, individuals no longer find themselves bound to traditional values, resulting in increased promiscuity and an increased vulnerability to HIV infection [93].

Finally, when discussing HIV and urbanization, it is important to consider opportunistic infection and comorbidities. Tuberculosis infection tends to be both more severe and more difficult to treat among patients with HIV. Opportunistic infections, including infections with molds and fungus, may be influenced by movement between rural and urban environments. The high-risk sexual behaviors that lead to HIV transmission also place individuals at risk of acquiring other sexually transmitted infections, including syphilis. Additionally, because injection drug use has primarily been an urban health issue, urbanization may lead to an increase in injection drug use and thus further the spread of HIV. Injection drug use with shared needles can transmit many other viruses in addition to HIV. Approximately one in five injection drug users (approximately 16 million worldwide) is HIV-positive [94]. HIV also increases the risk of hepatitis $\mathrm{C}$ virus ( $\mathrm{HCV}$ ) - almost a third of individuals with HIV are co-infected with HCV $[95,96]$.

These trends are not only a problem of the developing world. During the early stages of the HIV epidemic in the United States, for example, the first patients diagnosed with HIV and those at highest risk were white men who had sex with men living in urban areas. The HIV epidemic in the USA continues to be primarily an urban problem, with more than $80 \%$ of HIV diagnoses occurring in major metropolitan areas [97].

\subsection{Conclusions and Future Directions}

The world's population continues to grow exponentially, and more people are living in cities and megacities. This population growth, coupled with the interconnectedness of the entire world, has significant implications for disease. This chapter 
described major infectious disease threats in the urban environment, past and present, and illustrated several mechanisms by which urbanization can affect the epidemiology of infectious diseases (Table 4.1).

Urbanization disproportionately impacts the poor. Hence, not only "slum upgrading" but also prevention of slums will be important in order to mitigate the harmful effects of rapid urbanization. Further development of health systems in parallel with improved housing, sanitation, and access to clean water is necessary. Anticipating continued growth and expansion should prompt governments to dedicate additional resources to urban planning. Vaccination, monitoring and reporting of new cases, and ring chemoprophylaxis are critical for curtailing epidemics and pandemics. Disease surveillance systems and systems for communication and reporting are crucial [98]. Rapid innovations in information technology may inform the development of such systems.

Systems for epidemic response also must be strengthened. Rapid, early detection and diagnosis are keys to addressing any disease outbreak. Clinical diagnostic algorithms must be identified early and health providers educated about them, as laboratory diagnostic tools often take time to become available and affordable. Health-care workers should be targeted to receive treatment and prophylaxis as soon as possible. The manufacture and distribution of sufficient quantities of vaccine, treatment, and chemoprophylaxis during outbreaks is also a major challenge. Finally, processes for effective coordination of efforts among agencies involved in epidemic response must be developed in advance.

In terms of future directions, three topics merit further consideration on the urbanization and global health agenda: (1) bioterrorism, (2) nosocomial infections and the development of resistant organisms, and (3) noninfectious diseases (i.e., chronic diseases) in urbanizing areas. First, there is a need to address the looming threat of bioterrorism, which capitalizes on the epidemiologic principles discussed in this chapter. Four diseases are recognized to have significant bioterrorism potential in urban settings. This chapter has discussed two disease agents - plague and smallpox virus - which can spread from person to person. The other two are anthrax (spores) and botulism (toxin), which are not spread from person to person but could cause mass infection and death if released in aerosolized form into a crowded area or, in the case of botulinum toxin, into the food supply. Outbreak preparedness requires identification of vaccines and treatments for these potential threats, developers who would be able to produce vaccines and treatments should need arise, and a sophisticated system of targeted, efficient diagnosis, isolation, treatment, and, where necessary, vaccination, to curtail further spread.

Second, to the extent that urbanization influences the development of medical centers and affects the use of broad-spectrum antibiotics, nosocomial infections such as Clostridium difficile and resistant organisms such as methicillin-resistant Staphylococcus aureus (MRSA) and vancomycin-resistant Enterococcus (VRE) bear mentioning. MRSA is now found fairly widely in the community and may be more common in urban residents compared to rural residents [99]. Less common but of great concern is the emergence of vancomycin-resistant Staphylococcus aureus (VRSA). Only a few cases of VRSA have been reported in the USA to date [100], 


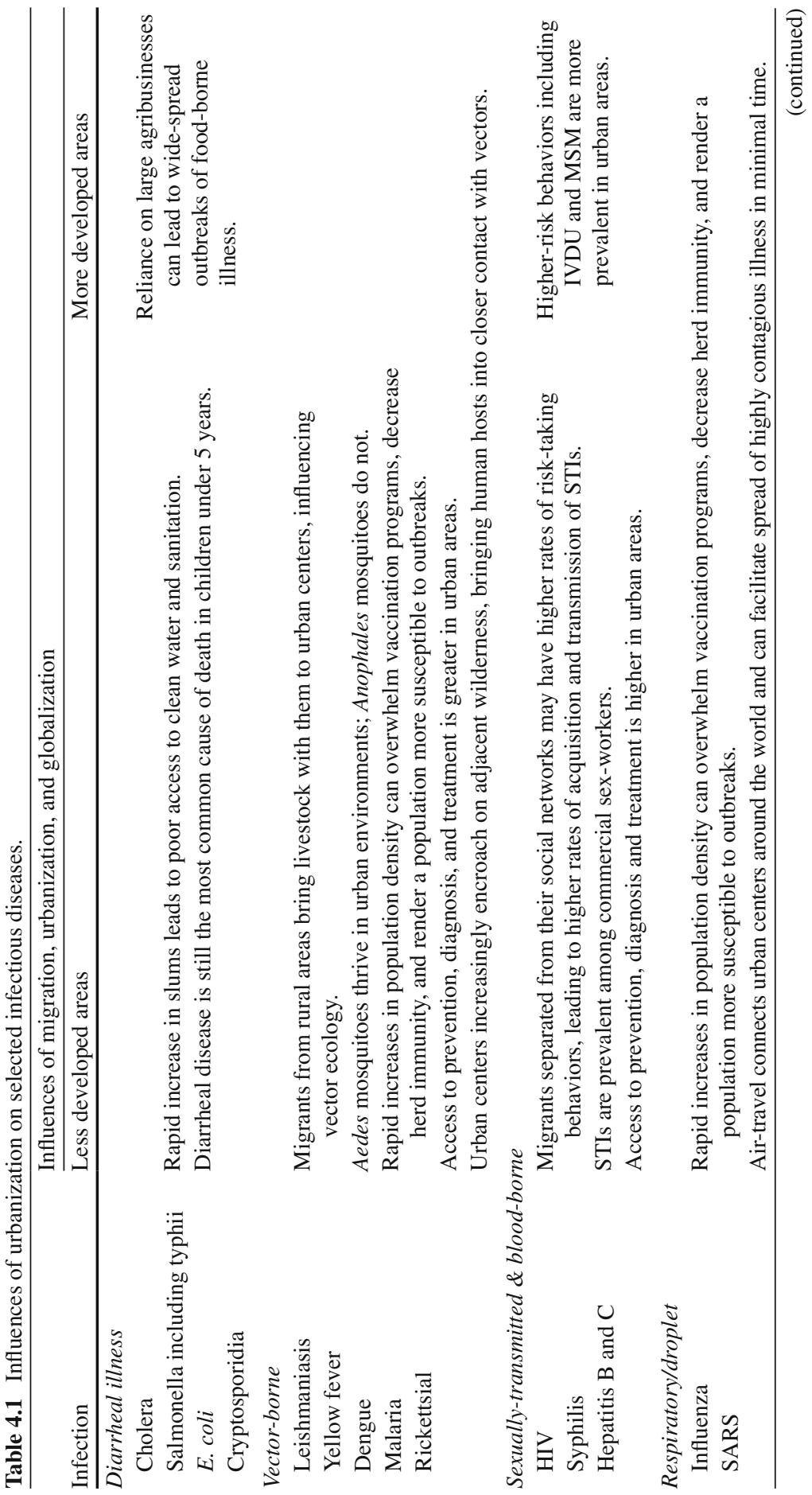




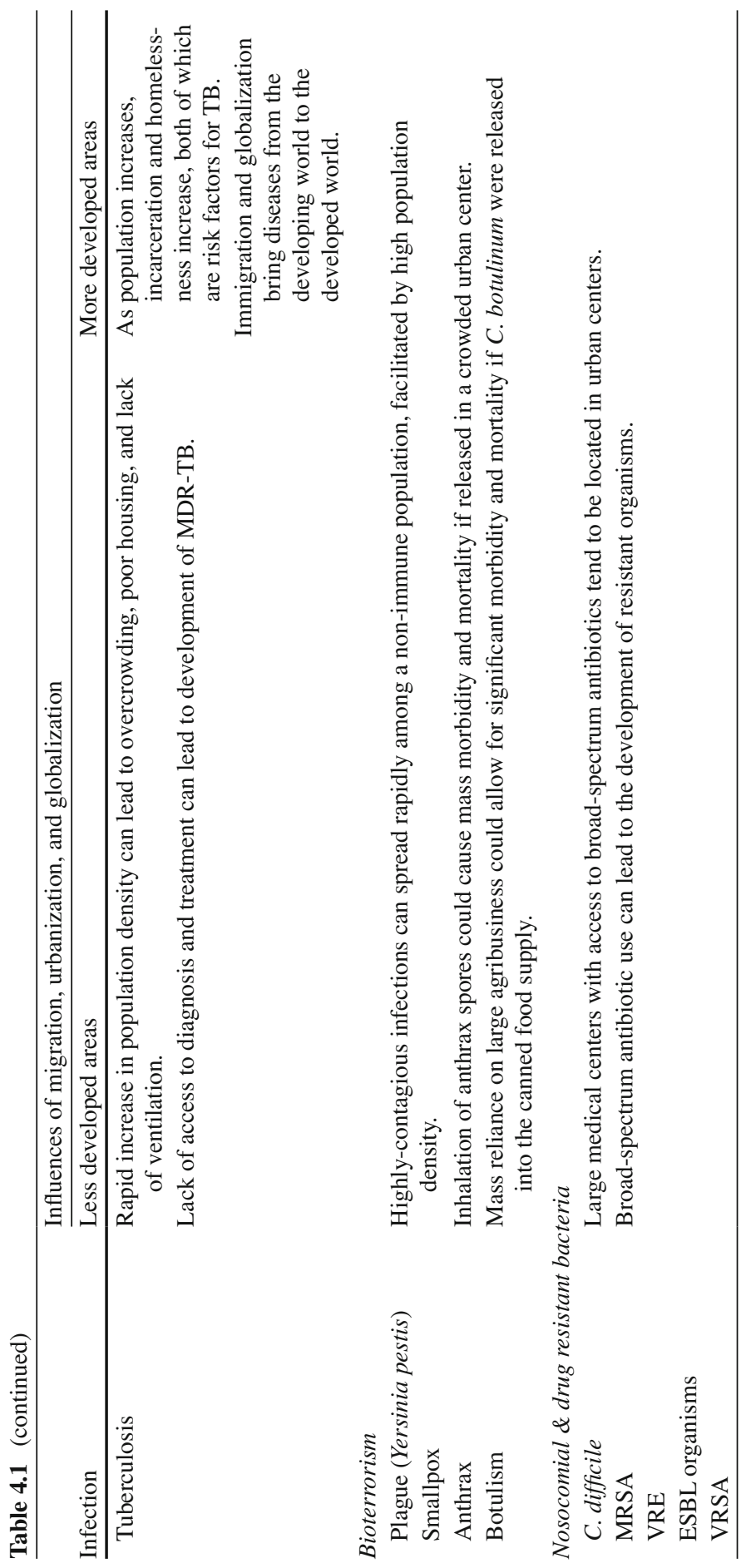


but they highlight the importance of judicious use of antibiotics as well as adherence to contact precaution protocols for hospitalized patients with suspected or confirmed resistant bacterial colonization.

Finally, it is important to acknowledge that a growing proportion of the global burden of disease is noncommunicable. Pollution, trauma, violence, and obesity all are major causes of death and disability that are on the rise with urbanization and globalization. Cardiovascular disease has been the leading cause of morbidity and mortality in both the developed and the developing world for the past 15 years [101]. This in part is due to improved control of infectious diseases and increasing lifespan (i.e., people are living long enough for cardiovascular disease to become salient) coupled with persistent, relatively higher rates of cigarette smoking in the developing world. More research in all aspects of chronic disease and urbanization processes need further elucidation.

Overall, urban centers pose great challenges in terms of disease, but they also present unique opportunities for health promotion and disease prevention. For example, the concentration of human and financial resources in cities can translate into greater capacity to carry out health campaigns in order to reduce the risk of transmission of diseases like HIV/AIDS and TB. Access to health education, condoms, disease diagnosis and treatment also may be greater in the urban centers compared to rural areas.

Urban centers have the potential to bring together a critical mass of people from multiple disciplines and sectors (e.g., medicine, health, economics, engineering, sociology, social work, architecture), harness collective knowledge, and foster an environment that promotes the development of innovative, integrative solutions to health problems. Ultimately, such holistic solutions are desperately needed to address the world's emerging urbanization and health threats.

Acknowledgments The authors wish to thank the following individuals for research and editorial assistance: Genevieve Purcell, Kathryn Tindell, Emily deRedon, Kathryn Conn, and Christine Cho.

\section{References}

1. United Nations, Department of Economic and Social Affairs, Population Division (2010) World urbanization prospects: the 2009 revision: highlights, New York

2. United Nations, Department of Economic and Social Affairs, Statistics Division (2010) Methods and classifications, population density and urbanisation, standards and methods, concepts and definitions, paras. 2.81-2.88 [Internet]. [cited 2011 Sept 8]. Available from: http://unstats.un.org/unsd/methods.htm

3. Principles of epidemiology in public health practice: an introduction to applied epidemiology and biostatistics, 3rd edn [Internet]. U.S. Department of Health and Human Services Centers for Disease Control and Prevention (CDC) Office of Workforce and Career Development, Atlanta, GA; [cited 2011 Feb 26]. Available from: http://www.cdc.gov/training/products/ ss1000/ss1000-ol.pdf 
4. Giesecke J (2007) Mathematical models for epidemics. In: Nelson KE, Williams CM (eds) Modern infectious disease epidemiology: theory and practice, 2nd edn. Oxford University Press Inc, New York, pp 200-214

5. Fenner F (1971) Infectious disease and social change: part 2. Med J Aust 1:1099-1102

6. Mangili A, Gendreau MA (2005) Transmission of infectious disease during commercial air travel. Lancet 365:989-996

7. Ward BJ, Plourde P (2006) Travel and sexually transmitted infections. J Travel Med 13:300-317

8. Plotkin SL, Plotkin SA (2008) A short history of vaccination. In: Plotkin SA, Orenstein WA, Offit PA (eds) Vaccines, 5th edn. Elsevier, China, pp 1-16

9. Riedel S (2005) Edward Jenner and the history of smallpox and vaccination. Proc (Bayl Univ Med Cent) 18:21-25

10. U.S. Department of Health and Human Services Centers for Disease Control and Prevention. Vaccines and immunizations [Internet]. Centers for Disease Control and Prevention, Atlanta, GA; 2011 Sept 1. Available from: http://www.cdc.gov/vaccines/default.htm

11. Orenstein WA, Pickering LK, Mawle A, Hinman AR, Wharton M (2010) Immunization. In: Mandell GL, Bennet JE, Dolin R (eds) Principles and practice of infectious disease, 7th edn. Churchill Livingstone Elsevier, Philadelphia, pp 3917-3946

12. The College of Physicians of Philadelphia (2011) The history of vaccines [Internet] [cited 2011 Sept 8]. Available from: http://www.historyofvaccines.org

13. Alirol E, Getaz L, Stoll B, Chappuis F, Loutan L (2011) Urbanisation and infectious diseases in a globalised world. Lancet Infect Dis 11:131-141

14. Dales LG, Kizer KW, Rutherford GW, Pertowski CA, Waterman SH, Woodford G (1993) Measles epidemic from failure to immunize. West J Med 159:456-464

15. Herlihy D, Cohn SK Jr (1997) The Black Death and the transformation of the West. Harvard University Press, Cambridge, MA

16. Cohn SK Jr (2008) Epidemiology of the Black Death and successive waves of plague. Med Hist Suppl 27:74-100

17. Prentice MB, Rahalison L (2007) Plague. Lancet 369:1196-1207

18. Sloan AW (1973) History of medicine: medical and social aspects of the great plague of London in 1665. S Afr Med J 47:270-276

19. Dennis DT, Mead PS (2010) Yersinia species, including plague. In: Mandell GL, Bennett JE, Raphael Dolin R (eds) Principles and practice of infectious diseases, 7th edn. Elsevier, Philadelphia, p 2943

20. Tikhomirov E (1999) Epidemiology and distribution of plague. In: Plague manual: epidemiology, distribution, surveillance and control. WHO, Geneva, pp 11-37

21. Gage KL (1999) Plague surveillance. In: Plague manual: epidemiology, distribution, surveillance and control. WHO, Geneva, pp 135-166

22. Johnson NP, Mueller J (2002) Updating the accounts: global mortality of the 1918-1920 "Spanish" influenza pandemic. Bull Hist Med 76:105-115

23. Nelson KE, Williams CM (2007) Early history of infectious disease: epidemiology and control of infectious diseases. In: Infectious disease epidemiology: theory and practice. Jones and Bartlett Publishers Inc, Sudbury, pp 3-23

24. Hatchett RJ, Mecher CE, Lipsitch M (2007) Public health interventions and epidemic intensity during the 1918 influenza pandemic. Proc Natl Acad Sci U S A 104:7582-7587

25. Morse SS (2007) Pandemic influenza: studying the lessons of history. Proc Natl Acad Sci U S A 104:7313-7314

26. Markel H, Lipman HB, Navarro JA et al (2007) Nonpharmaceutical interventions implanted by US cities during the 1918-1919 influenza pandemic. JAMA 298:644-654

27. Paulo A, Correia-Neves M, Domingos T, Murta A, Pedrosal J (2010) Influenza infectious dose may explain the high mortality of the second and third wave of 1918-1919 influenza pandemic. PLoS One 5:e11655

28. Yuen KY, Wong SSY, Malik Peiris JS (2010) The severe acute respiratory syndrome. In: Fong IW, Alibek K (eds) New and evolving infections of the 21st century. Springer, New York, pp 163-193 
29. Affonso DD, Andrews GJ, Jeffs L (2004) The urban geography of SARS: paradoxes and dilemmas in Toronto's health care. J Adv Nurs 45:568-578

30. Svoboda T, Henry B, Shulman L et al (2004) Public health measures to control the spread of the severe acute respiratory syndrome during the outbreak in Toronto. N Engl J Med 350:2352-2361

31. de Jong MD (2010) Avian influenza viruses and pandemic influenza. In: Fong IW, Alibek K (eds) New and evolving infections of the 21st century. Springer, New York, pp 327-359

32. The Writing Committee of the World Health Organization (WHO) Consultation on Human Influenza A/H5 (2005) Avian influenza A (H5NI) infections in humans. N Engl J Med 353:1374-1385

33. Belshe RB (2005) The origins of pandemic influenza - lessons from the 1918 virus. N Engl J Med 353:2209-2211

34. Guan Y, Vijaykrishna D, Bahl J, Zhu H, Wang J, Smith GJ (2010) The emergence of pandemic influenza viruses. Protein Cell 1:9-13

35. Taubenberger JK, Morens DM (2010) Influenza: the once and future pandemic. Public Health Rep 125(Suppl 3):16-26

36. Khan K, Arino J, Hu W et al (2009) Spread of a novel influenza A (H1N1) virus via global airline transportation. N Engl J Med 361:212-214

37. World Health Organization (2008) Our cities, our health, our future: acting on social determinants for health equity in urban settings. World Health Organization Centre for Health Development, Kobe

38. World Health Organization and United Nation Children's Fund Joint Monitoring Programme for Water Supply and Sanitation (JMP) (2008) Progress on drinking water and sanitation: special focus on sanitation. UNICEF/WHO, New York/Geneva

39. Expert Meeting Group Report (2004) Expert consensus. In: Cotruvo JA, Dufour A, Rees G et al (eds) Waterborne zoonoses: identification, causes and control. IWA Publishing on behalf of World Health Organization, London, pp 3-16

40. Moe CL (2004) What are the criteria for determining whether a disease is zoonotic and water related? In: Cotruvo JA, Dufour A, Rees G et al (eds) Waterborne zoonoses: identification, causes and control. IWA Publishing on behalf of World Health Organization, London, pp $27-45$

41. Kigotho AW (1998) Cholera hits east African cities. Lancet 351:45

42. Deen JL, von Seidlein L, Sur D et al (2008) The high burden of cholera in children: comparison of incidence from endemic areas in Asia and Africa. PLoS Negl Trop Dis 2:e173

43. Kimani-Murage EW, Ngindu AM (2007) Quality of water the slum dwellers use: the case of a Kenyan slum. J Urban Health 84:829-838

44. Bhunia R, Hutin Y, Ramakrishnan R, Pal N, Sen T, Murhekar M (2009) A typhoid fever outbreak in a slum of South Dumdum municipality, West Bengal, India, 2007: evidence for foodborne and waterborne transmission. BMC Public Health 9:115

45. Copeland CC, Beers BB, Thompson MR et al (2009) Faecal contamination of drinking water in a Brazilian shanty town: importance of household storage and new human faecal marker testing. J Water Health 7:324-331

46. International Network to Promote Household Water Treatment and Safe Storage (2007) Combating waterborne disease at the household level. World Health Organization, Geneva

47. Brick T, Primrose B, Chandrasekhar R, Roy S, Muliyil J, Kang G (2004) Water contamination in urban south India: household storage practices and their implications for water safety and enteric infections. Int J Hyg Environ Health 207:473-480

48. Butala NM, Vanrooyen MJ, Patel RB (2010) Improved health outcomes in urban slums. Soc Sci Med 71:935-940

49. Gubler DJ (1998) Epidemic dengue and dengue hemorrhagic fever: a global public health problem in the 21 st century. In: Scheld WM, Armstrong D, Hughes JM (eds) Emerging infections I. ASM Press, Washington, DC, pp 1-14

50. Vazquez-Prokopec GM, Kitron U, Montgomery B, Horne P, Ritchie SA (2010) Quantifying the spatial dimension of dengue virus epidemic spread within a tropical urban environment. PLoS Negl Trop Dis 4(12):e920 
51. Desjeux P (2004) Leishmaniasis: current situation and new perspectives. Comp Immunol Microbiol Infect Dis 27:305-318

52. Roll Back Malaria. Children and malaria [Internet]. World Health Organization; [cited 2011 June 23]. Available from: http://www.rollbackmalaria.org/cmc_upload/0/000/015/367/ RBMInfosheet_6.htm

53. World Health Organization (2010) Malaria fact sheet No. 94 [Internet]. World Health Organization, Geneva; [cited 2011 Apr 14]. Available from: http://www.who.int/mediacentre/ factsheets/fs094/en/

54. Hay SI, Guerra CA, Tatem AJ, Atkinson PM, Snow RW (2005) Urbanization, malaria transmission and disease burden in Africa. Nat Rev Microbiol 3:81-90

55. Kallander K, Nsungwa-Sabiiti J (2009) Home-based management of malaria in the era of urbanisation. Lancet 373:1582-1584

56. Tatem AJ, Guerra CA, Kabaria CW, Noor AM, Hay SI (2008) Human population, urban settlement patterns and their impact on Plasmodium falciparum malaria endemicity. Malar J $7: 218$

57. Kasili S, Odemba N, Ngere FG, Kamanza JB, Muema AM, Kutima HL (2009) Entomological assessment of the potential for malaria transmission in Kibera slum of Nairobi, Kenya. $\mathrm{J}$ Vector Borne Dis 46:273-279

58. Robert V, Macintyre K, Keating J, Trape JF, Duchemin JB, Warren M, Beier JC (2003) Malaria transmission in urban sub-Saharan Africa. Am J Trop Med Hyg 68:169-176

59. Keiser J, Utzinger J, CladasdeCastro M, Smith TA, Tanner M, Singer BH (2004) Urbanization in sub-Saharan Africa and implications for malaria control. Am J Trop Med Hyg 71(Suppl 2):118-127

60. Tiwari S, Ghosh SK, Ojha VP, Dash AP, Raghavendra K (2010) Reduced susceptibility to selected synthetic pyrethroids in urban malaria vector Anopheles stephensi: a case study in Mangalore city, South India. Malar J 9:179

61. Klinkenberg E, McCall PJ, Wilson MD, Akoto AO, Amerasinghe FP, Bates I et al (2006) Urban malaria and anaemia in children: a cross-sectional survey in two cities in Ghana. Trop Med Int Health 11:578-588

62. Siri JG, Wilson ML, Murray S, Rosen DH, Vulule JM, Slutsker L, Lindblade KA (2010) Significance of travel to rural areas as a risk factor for malarial anemia in an urban setting. Am J Trop Med Hyg 82:391-397

63. World Health Organization (2010) Global tuberculosis control: WHO report 2010. World Health Organization, Geneva

64. Lonnroth K, Jaramillo E, Williams BG, Dye C, Raviglione M (2009) Drivers of tuberculosis epidemics: the role of risk factors and social determinants. Soc Sci Med 68:2240-2246

65. Wood R, Liang H, Wu H et al (2010) Changing prevalence of tuberculosis infection with increasing age in high-burden townships in South Africa. Int J Tuberc Lung Dis 14:406-412

66. Hargreaves JR, Boccia D, Evans CA, Adato M, Petticrew M, Porter JDH (2011) The social determinants of tuberculosis: from evidence to action. Am J Public Health 101:654-662

67. Corbett EL, Bandason T, Cheung YB et al (2009) Prevalent infectious tuberculosis in Harare, Zimbabwe: burden, risk factors and implications for control. Int J Tuberc Lung Dis 13:1231-1237

68. David AM, Mercado SP, Becker D, Edmundo K, Mugisha F (2007) The prevention and control of HIV/AIDS, TB and Vector-borne diseases in informal settlements: challenges, opportunities and insights. J Urban Health 84:65-74

69. Alvarez-Hernandez G, Lara-Valencia F, Reyes-Castro PA, Rascon-Pacheco RA (2010) An analysis of spatial and socio-economic determinants of tuberculosis in Hermosillo, Mexico, 2000-2006. Int J Tuberc Lung Dis 14:708-713

70. Suganthi P, Chadha VK, Ahmed J et al (2008) Health seeking and knowledge about tuberculosis among persons with pulmonary symptoms and tuberculosis cases in Bangalore slums. Int J Tuberc Lung Dis 12:1268-1273

71. Wang W, Wang J, Zhao Q, Darling ND, Yu M, Zhou B, Xu B (2011) Contribution of rural-tourban migration in the prevalence of drug resistant tuberculosis in China. Eur J Clin Microbiol Infect Dis 30:581-586 
72. Udwadia ZF, Pinto LM, Uplekar MW (2010) Tuberculosis management by private practitioners in Mumbai, India: has anything changed in two decades? PLoS One 5:e12023

73. Karande S, Bavdekar SB (2002) Children and multidrug-resistant tuberculosis in Mumbai (Bombay), India. Emerg Infect Dis 8:1360-1361

74. Telles MA, Ferrazoli L, Waldman EA et al (2005) A population-based study of drug resistance and transmission of tuberculosis in an urban community. Int $\mathrm{J}$ Tuberc Lung Dis 9:970-976

75. Hasan R, Jabeen K, Ali A et al (2010) Extensively drug-resistant tuberculosis, Pakistan. Emerg Infect Dis 16:1473-1475

76. Zhao M, Li X, Xu P et al (2009) Transmission of MDR and XDR tuberculosis in Shanghai, China. PLoS ONE 4:e4370

77. Centers for Disease Control and Prevention (2007) Extensively drug-resistant tuberculosis United States, 2003-2006. MMWR Morb Mort Wkly Rep 56:250-253

78. Almeida D, Rodrigues C, Udwadia ZF, Lalvani A, Gothi GD, Mehta P, Mehta A (2003) Incidence of multi-drug resistant tuberculosis in urban and rural India and implications for prevention. Clin Infect Dis 36:e152-e154

79. Tang S, Squire SB (2005) What lessons can be drawn from tuberculosis (TB) control in China in the 1990s? An analysis from a health system perspective. Health Policy 72:93-104

80. Long Q, Li Y, Wang Y et al (2008) Barriers to accessing TB diagnosis for rural-to-urban migrants with chronic cough in Chongqing, China: a mixed methods study. BMC Health Serv Res 8:202

81. Joint United Nations Programme on HIV/AIDS (UNAIDS) (2010) UNAIDS report on the global AIDS epidemic 2010. UNAIDS, Geneva

82. UNAIDS (2008) Report on the global AIDS epidemic. UNAIDS, Geneva

83. Greif MJ, Nii-Amoo Dodoo F (2011) Internal migration to Nairobi's slums: linking migrant streams to sexual risk behavior. Health Place 17:86-93

84. Zulu EM, Nii-Amoo Dodoo F, Chika-Ezeh A (2002) Sexual risk-taking in the slums of Nairobi, Kenya, 1993-98. Popul Stud (Camb) 56:311-323

85. Li L, Morrow M, Kermode M (2007) Vulnerable but feeling safe: HIV risk among male ruralto-urban migrant workers in Chengdu, China. AIDS Care 19:1288-1295

86. Li S, Huang H, Cai Y, Xu G, Huang F, Shen X (2009) Characteristics and determinants of sexual behavior among adolescents of migrants workers in Shangai (China). BMC Public Health 9:195

87. Roy T, Anderson C, Evanas C, Rahman MS (2010) Sexual risk behaviour of rural-to-urban migrant taxi drivers in Dhaka, Bangladesh: a cross-sectional behavioural survey. Public Health 124:648-658

88. Sarkar K, Bal B, Mukherjee R, Niyogi SK, Saha MK, Bhattacharya SK (2005) Epidemiology of HIV infection among brothel-based sex workers in Kolkata, India. J Health Popul Nutr 23:231-235

89. Silverman JG, Decker MR, Gupta J, Maheshwari A, Willis BM, Raj A (2007) HIV prevalence and predictors of infection in sex-trafficked Nepalese girls and women. JAMA 298:536-542

90. Dharmadhikari AS, Gupta J, Decker MR, Raj A, Silverman JG (2009) Tuberculosis and HIV: a global menace exacerbated via sex trafficking. Int J Infect Dis 13:543-546

91. Quinn TC(1994) Population migration and the spread of types 1 and 2 human immunodeficiency viruses. Proc Natl Acad Sci U S A 91:2407-2414

92. Greif MJ, Nii-Amoo Dodoo F, Jayaraman A (2011) Urbanisation, poverty and sexual behaviour: the tale of five African cities. Urban Stud 48:947-957

93. Buve A, Bishikwabo-Nsarhaza K, Mutangadura G (2002) The spread and effect of HIV-1 infection in sub-Saharan Africa. Lancet 359:2011-2017

94. Vlahov D, Robertson AM, Strathdee SA (2010) Prevention of HIV Infection among injection drug users in resource-limited settings. Clin Infect Dis 50(Suppl 3):S114-S121

95. Fleming CA, Crave DE, Thornton D, Tumilty S, Nunes D (2003) Hepatitis C virus and human immunodeficiency virus coinfection in an urban population: low eligibility for interferon treatment. Clin Infect Dis 36:97-100 
96. Shepard CW, Finelli L, Alter MJ (2005) Global epidemiology of hepatitis C virus infection. Lancet 5:558-567

97. Centers for Disease Control and Prevention (2008) Cases of HIV infection and AIDS in urban and rural areas of the United States, 2006. HIV AIDS Surveill Supplemental Report [serial online] [cited 2011 Jun 20] 13. Available from: http://www.cdc.gov/hiv/topics/ surveillance/resources/reports/2008supp_vol13no2/default.htm

98. Patel RB, Burke TF (2009) Global health: urbanization - an emerging humanitarian disaster. New Engl J Med 361:741-743

99. Anwar MS, Jaffery G, Rehman Bhatti KU, Tayyib M, Bokhari SR (2004) Staphylococcus aureus and MRSA nasal carriage in general population. J Coll Physicians Surg Pak 14(11):661-664

100. Chang S, Sievert DM, Hageman JC et al (2003) Infection with vancomycin-resistant Staphylococcus aureus containing the vanA resistance gene. N Engl J Med 348:1342-1347

101. Pearson T (1999) Cardiovascular disease in developing countries: myths, realities, and opportunities. Cardiovasc Drugs Ther 13:95-104 